\title{
Nível de consciência infantil sobre zoonoses e posse responsável em Uruguaiana- RS e Passo de Los Libres- AR
}

\section{Child awareness level about zoonoses and responsible possession in Uruguaiana- RS and Passo de Los Libres- AR}

\author{
Julia Pasa Brandt ${ }^{1}$, Vitória Souza Debastiani², Dimas Dal Magro Ribeiro ${ }^{3}$, Danielly Trindade \\ Marinho $^{4}$, Deise Dalazen Castagnara ${ }^{5}$, Liane Santariano Sant'Anna ${ }^{6}$.
}

\begin{abstract}
RESUMO
Animais de estimação estão cada vez mais presentes nos lares em todo o mundo. E, por possuirem potencial na transmissão de zoonoses representam um risco à saúde pública. Objetivou-se com este, verificar o nível de consciência sobre zoonoses e posse responsável em crianças com idade escolar dos municípios de Uruguaiana, Rio Grande do Sul, Brasil e Passo de Los Libres, Corrientes, Argentina. Ao todo, atenderamse 11 escolas, totalizando 341 crianças do $3^{\circ}$ ao $5^{\circ}$ ano. Destas $90 \%$ possuíam animais de estimação, dos quais aproximadamente $70 \%$ nas escolas brasileiras e 58,33\% nas escolas argentinas eram cães. Na adoção, 90\% das crianças compreendem ser a melhor opção para obtenção de um animal de estimação. Já, sobre zoonoses, mais de $50 \%$ das crianças desconheciam o conceito da palavra. Constatou-se que conhecimentos sobre posse responsável e zoonoses são limitados, porém, há preocupação dos tutores com os animais. Nos locais do estudo há grande potencial para trabalhos de conscientização, podendo estender-se aos pais das crianças. Também, nestes trabalhos de conscientização devem estar contempladas a posse responsável, bem-estar animal e saúde pública com foco em zoonoses.
\end{abstract}

Palavras-chave: Animais Pet ${ }^{1}$; Doenças ${ }^{2}$; Crianças $^{3}$.

\section{ABSTRACT}

Pets are increasingly present in homes around the world. And, because they have the potential to transmit zoonoses, they represent a risk to public health. The objective of this study was to verify the level of awareness about zoonoses and responsible possession in school-age children from the municipalities of Uruguaiana, Rio Grande do Sul, Brazil and Passo de Los Libres, Corrientes, Argentina. In all, 11 schools were attended, totaling 341 children from the 3rd to the 5th grade. Of these, $90 \%$ had pets, of which approximately $70 \%$ in Brazilian schools and $58.33 \%$ in Argentine schools were dogs. In adoption, $90 \%$ of children understand that it is the best option for obtaining a pet. As for zoonoses, more than $50 \%$ of children were unaware of the concept of the word. It was found that knowledge about responsible ownership and zoonoses is limited, however, there is concern of tutors with animals. In the study sites, there is great potential for awareness-raising work, which could be extended to the children's parents. Also, in these awareness-raising works, responsible ownership, animal welfare and public health with a focus on zoonoses should be considered.

Keywords: Pets ${ }^{1}$; Disease ${ }^{2}$; Children ${ }^{3}$.

${ }^{1}$ Universidade Federal do Pampa

E-mail: juliabrandt.aluno@unipampa.edu.br 


\section{INTRODUÇÃO}

Os problemas relacionados com o abandono animal estão distribuídos em todo o mundo, uma vez que esta prática tem múltiplas causas nas diversas sociedades. Segundo a World Veterinary Association, há uma média de 200 milhões de cães abandonados no mundo. No Brasil, aproximadamente 30 milhões de animais vivem em situação de abandono (SCHEFFER, 2018). Na maior parte dos municípios brasileiros há superpopulação de cães não domiciliados, os quais trazem problemas associados à ordem urbana, ao meio ambiente e à saúde coletiva, além de sofrerem maus-tratos (MOUTINHO et al., 2015).

No município de Uruguaiana, localizado na Fronteira Oeste do Rio Grande do Sul, a situação não é diferente (BRANDT et al., 2021). Estudos comprovaram um elevado número de cães e gatos errantes (BORTOLOTI et al. 2012), e ainda, devido ao fator cultural, no município também é comum o abandono de equinos (BRANDT et al., 2021).

A existência de animais abandonados nas ruas de um município demonstra uma fragilidade na consciência da população a respeito da posse responsável, pois o alto índice de animais nas ruas é, sem dúvidas, consequência dos maus-tratos (BORTOLOTI et al. 2012) e da falta de informação nos lares dos munícipes (BRANDT et al., 2021). Ainda, na cidade de Uruguaiana o número de cães e gatos errantes é notadamente elevado, o que causa uma preocupação ainda maior em relação á saúde pública (BRANDT et al., 2021).

$\mathrm{O}$ aumento populacional de animais abandonados deve-se à irresponsabilidade de alguns tutores de cães e gatos, e à procriação descontrolada (BRANDT et al., 2021). Nas sociedades, o crescimento populacional destes animais é alto e passou a constituir problemas sociais e causar implicações para a saúde pública, dentre estas, a transmissão de zoonoses (SILVA et al., 2021).

Embora animais abandonados no perímetro urbano e rural façam parte da rotina de grandes e pequenas cidades, não significa que devamos aceitar como normal a citada situação, especialmente devido ao risco de zoonoses que estes animais representam. Sabese que múltiplas causas como religiosas, culturais e socioeconômicas culminam com este abandono animal (GARCIA et al., 2012), não sendo diferente no município de Uruguaiana (SILVA et al., 2013). Campanhas de adoção, trabalhos de ONGs dentre outros tentam amenizar o problema, porém, com resultados pouco expressivos (BRANDT et al., 2021). Ainda, por algum tempo o controle populacional de animais errantes foi 
realizado por meio do recolhimento e extermínio, porém, trata-se de um método ineficiente. Essa ineficiência decorre de vários motivos, tais como a ocupação do ambiente por novos animais, rápida reprodução e falta de guarda responsável quanto à sanidade, castração dos animais e restrição do livre acesso às ruas (Molento, 2014).

Nesse contexto, vislumbra-se a necessidade do desenvolvimento de ações de controle populacional desses animais (MOUTINHO et al., 2015). Contudo, devido à dinâmica populacional destes, o método de controle considerado mais eficaz é a esterilização (SCHEFFER, 2018). Entretanto, é um método demorado e dispendioso economicamente para ser aplicado pelos municípios. Neste contexto, são valiosos os trabalhos de conscientização da população, especialmente das crianças na fase de aprendizado (TOME et al., 2005), pois a organização do espaço de convívio da criança é fator estimulante ao desenvolvimento da sua personalidade (LOPES et al., 2005).

Quando exposta à um ambiente com situações que lhe permitam interpretar posturas compatíveis com a vida em sociedade e o respeito com os animais, as mesmas podem atuar como agentes multiplicadores da informação (DIAS et al., 2012), podendo de fato, permitir a expectativa de mudança cultural/educacional de uma sociedade. Assim, objetivou-se com este trabalho realizar a conscientização de crianças no município de Uruguaiana sobre posse animal responsável e sua importância para a saúde pública.

\section{METODOLOGIA}

O trabalho foi desenvolvido em escolas municipais e particulares do município de Uruguaiana, Rio Grande do Sul - Brasil e Passo de Los Libres, Corrientes - Argentina, por acadêmicos do curso de Medicina Veterinária. As visitas foram realizadas no período de junho a julho de 2017. As ações contemplaram crianças com faixa etária de 05 a 07 anos. Estas ações foram compostas pela exposição de material e conteúdo ilustrados educativos, realização de jogos e atividades socioeducativas. Esses materiais foram elaborados com uma linguagem simples e objetiva compatível com a faixa etária abordada. Após a elaboração dos materiais os mesmos foram validades pela pedagoga institucional da Universidade Federal do Pampa e pelas pedagogas das escolas.

Para o diagnóstico do conhecimento das crianças sobre a relação entre posse responsável e o risco de zoonoses, eram apresentadas imagens ilustrativas de cães e humanos sob condições de risco para transmissão de zoonoses. Após a apresentação das imagens as crianças eram questionadas sobre o que aquela imagem representava. Para 
cada figura eram aceitas as manifestações de três crianças, e após as manifestações todos eram indagados sobre a concordância ou não com a manifestação do colega. A quantificação era feita por meio de contagem das crianças que levantavam a mão concordando com tal manifestação.

As perguntas contemplaram se as crianças possuíam ou não animal de estimação, qual era a espécie, se a melhor maneira de adquirir um animal era por compra ou adoção, se conheciam zoonoses e castração, qual doença era transmitida pela mordida do cão, e se os passeios eram importantes para o bem-estar dos animais.

Após as perguntas as respostas eram contabilizadas e registradas em planilha e também registradas por meio de registros audiovisuais para posterior conferência. Após o registro das informações realizava-se a explanação com os esclarecimentos sobre as perguntas realizadas. Após a coleta de dados e imagens, os mesmos foram tabulados em planilha Excel, analisados descritivamente e apresentados na forma de gráficos.

\section{RESULTADOS E DISCUSSÃO}

Foram visitadas 11 escolas, com abordagem de um total de 341 crianças compreendidas entre o $3^{\circ} ; 4^{\circ}$ e $5^{\circ}$ ano. Observou-se intensa participação das mesmas com vasta interação com os acadêmicos, além da participação das professoras estimulando as crianças a interagirem. Essa participação gerou um ambiente confortável e acolhedor e foi obtida em todas as escolas, permitindo a realização das apresentações de conscientização de uma forma mais instigante com as crianças, deixando-as mais empolgadas para levar para seus lares e compartilhar os conhecimentos adquiridos.

Ao serem questionadas se possuíam animais de estimação, a grande maioria das crianças, cerca de $90 \%$ (Figura 1) possuía animais de estimação em suas casas. Esse expressivo número de crianças que possui animais de estimação em suas casas reflete um aumento no número de animais em lares do município de Uruguaiana, pois Brandt et al., (2021) em estudo realizado anteriormente à este constatou $79 \%$ de presença de animais de estimação em lares de crianças da mesma faixa escolar. Tanto o aumento do número de animais quanto a expressividade encontrada reforçam a importância de campanhas de conscientização voltadas para crianças, pois ao conviverem diariamente com seus animais de estimação e interagirem com os adultos, as crianças os cativam, reduzindo as chances de abandono e maus tratos (DIAS et al. 2012). Como conhecemos que dentre as principais causas de abandono animal estão os problemas comportamentais dos animais, problemas 
relacionados à falta de espaço nas moradias, bem como o estilo de vida dos proprietários, a falta de informação sobre as responsabilidades e custos gerados pela guarda de animais (ALVES et al., 2013), campanhas que disseminem essas informações são fundamentais.

Ainda com a evolução da sociedade e a intensa urbanização dos ambientes, as pessoas tornaram-se cada vez mais distantes e isoladas (DELARISSA, 2003) e propensas à problemas emocionais e afetivos. Nesse contexto, a presença de animais de estimação nas famílias fez-se essencial e eles passaram a ser considerados como membro dos lares (SEGATA, 2012). Inúmeros são os benefícios proporcionados pela presença de animais de estimação em ambientes familiares, tanto para adultos quanto para crianças (Brandt et al., 2021). Dentre estes benefícios podemos citar a diminuição dos casos de depressão, do estresse, da ansiedade, a melhoria de humor, o aumento de estimulo para realização de atividades saudáveis, maior socialização de idosos e de pessoas com deficiências físicas e mentais, além de melhorar o aprendizado e socialização de crianças (Oliveira-Neto, 2018).

Figura 1 - Percentual de crianças de escolas públicas e particulares de Uruguaiana, Rio Grande do Sul - Brasil e Passo de Los Libres, Corrientes - Argentina que possuem animais de estimação em suas casas.

Você possui animal de estimação?

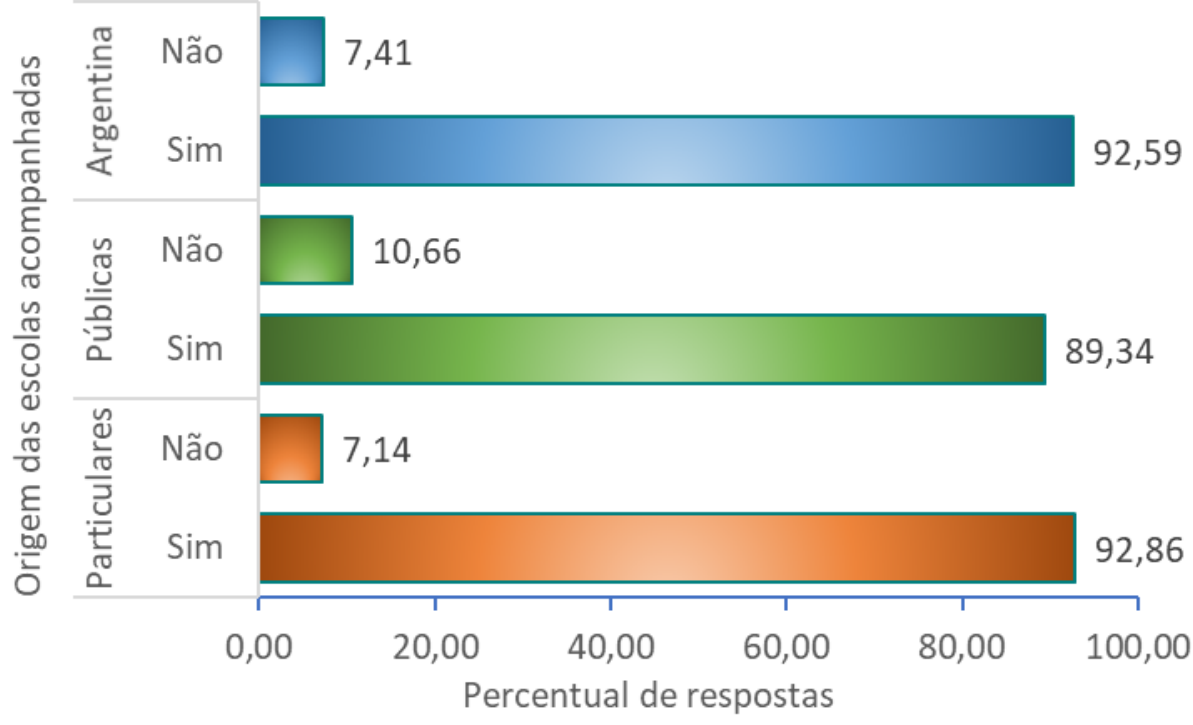

Fonte: Elaborado pelos autores

Quando questionadas sobre a espécie dos animais de estimação de suas casas, observou-se uma predominância de cães, de aproximadamente $70 \%$ nas escolas 
brasileiras e 58,33\% nas escolas argentinas, porém, nestas, o percentual de gatos foi mais expressivo (41,67\%). Embora a domesticação dos cães seja mais antiga do que dos gatos, ambos possuem grande capacidade de desenvolvimento de vínculo afetivo com seus tutores pois desde os primórdios da humanidade, estes animais sempre estiveram ao lado dos homens (TEIXEIRA et al. 2016) nas diferentes atividades do cotidiano, fazendo parte das refeições, do trabalho ou, simplesmente, como companhia. Cães e gatos, fazem parte da história das diferentes sociedades, pois enquanto os cães eram usados para caça e guarda nas sociedades primitivas, no Egito Antigo (DOTTI 2014), os gatos eram considerados animais sagrados e eram venerados pelas diferentes classes sociais, indo desde os escravos até os faraós, topo da pirâmide hierárquica egípcia.

Figura 2 - Percentual de cães e gatos obtidos como animais de estimação de crianças de escolas públicas e particulares de Uruguaiana, Rio Grande do Sul - Brasil e Passo de Los Libres,

Corrientes - Argentina.

\section{Seu animal de estimação é um cão ou gato?}

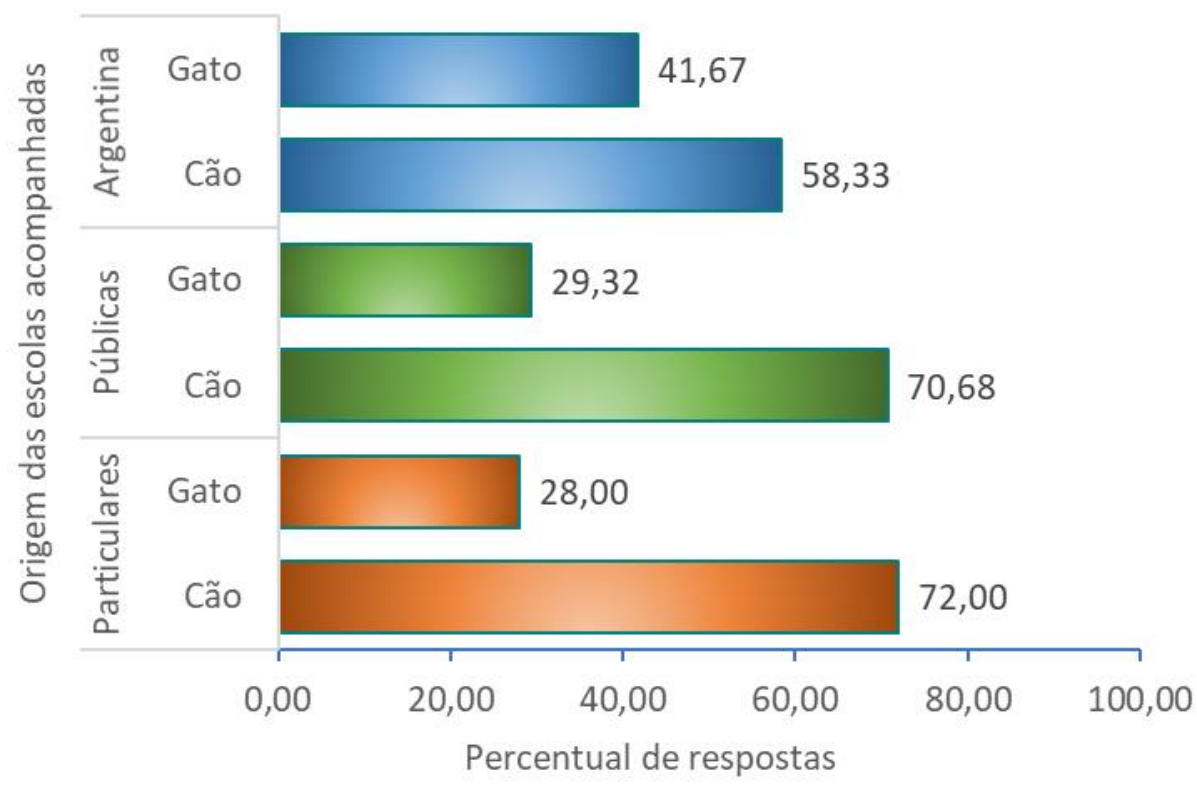

Fonte: Elaborado pelos autores

Com a evolução da sociedade estes animais passaram a viver dentro dos lares e fazer parte das famílias, trazendo consigo os benefícios proporcionados, mas também os riscos quando não recebem os cuidados necessários para sua saúde (BRANDT et al., 2021). Além destes riscos, é aumentado o risco de abandono animal quando não há o planejamento familiar para adoção ou compra de um animal de estimação. Embora seja 
crescente no Brasil o número de leis municipais relacionadas ao bem-estar animal, devido à pressão de setores da sociedade, os animais abandonados continuam sendo um problema, porém, de responsabilidade da própria sociedade (ALVES et al., 2013) cuja solução é dependente de campanhas de educação e conscientização.

$\mathrm{Na}$ indagação sobre a melhor forma de obtenção de um animal de estimação, nas escolas argentinas de Passo de Los Libres e da rede pública de Uruguaiana, mais de 90\% das crianças possuem a compreensão de que a adoção seria a melhor alternativa para adquirir um animal de estimação (Figura 3). Entretanto, nas escolas da rede privada de Uruguaiana esse percentual foi bem inferior $(65,96 \%)$ e $34,04 \%$ das crianças acreditam que os animais de estimação devem ser comprados e não adotados. Considerando que a adoção é a alternativa sugerida pela WSPA para aquisição de animais de estimação, os dados observados nas escolas privadas são preocupantes, e por este motivo, por ocasião da realização do projeto as crianças foram orientadas sobre a importância da adoção. Ainda, além da conscientização, a WSPA sugere que os futuros proprietários de cães e gatos, pensem na adoção como forma de adquirir um animal de estimação, pois muitos cães em abrigos esperam por um lar (DANTAS-LOSS et al., 2012). Ainda, Silva et al. (2021) constaram que um alto percentual de cães de abrigos são saudáveis e com bom escore corporal logo após seu recolhimento das ruas, indicando recente abandono ou semidomiciliação. Ou seja, seriam animais ideiais para adoção por apesar de terem passdo pelo sofrimento do abandono, ainda não passaram pelo sofrimento de anos de recolhimento em abrigos superpopulosos. Essa superpopulação de animais em abrigos é originada do descontrole da população de cães e gatos nas ruas a qual é percebida pela sociedade como um problema, tanto pelo risco de zoonoses quanto pelo reconhecimento, mais recente, do sofrimento animal (ARRUDA et al., 2019). A percepção sobre o sofrimento animal é um grande avanço e uma grande oportunidade para campanhas de conscientização e o controle populacional racional através da educação, especialmente voltada para crianças. 
Figura 3 - Consciência de crianças de escolas públicas e particulares de Uruguaiana, Rio Grande do Sul - Brasil e Passo de Los Libres, Corrientes - Argentina sobre a compra ou adoção de animais de estimação.

A melhor opção para ter um animal de estimação é a compra ou a adoção?

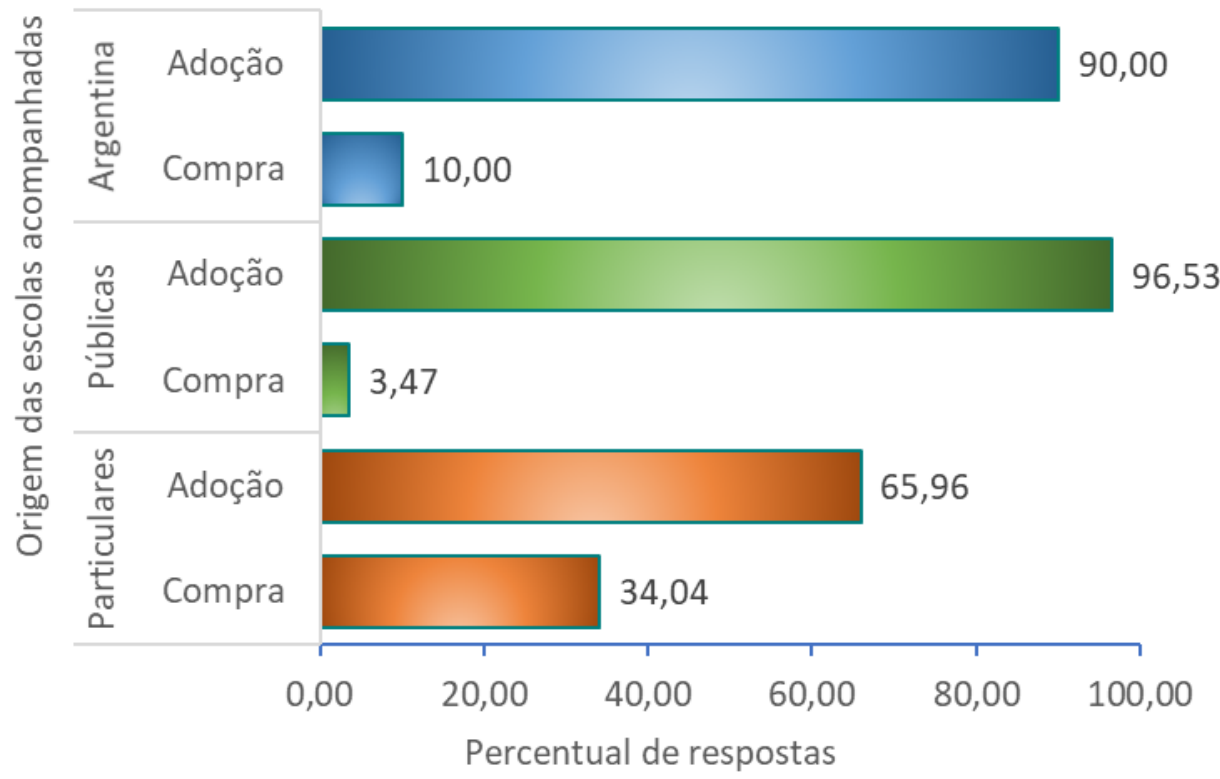

Fonte: Elaborado pelos autores

Em se tratando da castração, em escolas argentinas e da rede pública brasileira um percentual significativo de crianças conhecia os benefícios da prática para os animais (Figura 4). Possivelmente em função do custo da castração possuir maior representatividade no orçamento familiar, este era discutido e presenciado pelas crianças que desenvolviam essa consciência. Também, as crianças, ao solicitarem filhotes de seus animais aos seus pais eram orientadas sobre a necessidade e dificuldade de doação dos mesmos depois, compreendendo a importância da castração. Em escolas particulares de Uruguaiana, apenas $27,91 \%$ das crianças compreendiam a importância da realização da castração, possivelmente porque seus animais de estimação já eram adquiridos castrados, ou porque este assunto não fazia parte das conversas no núcleo familiar. Entretanto, apesar da representatividade dos percentuais de crianças conscientes sobre o tema, ainda há grande percentual que desconhece a importância da prática, o que evidencia a necessidade de continuidade das campanhas de conscientização. 
Figura 4 - Consciência de crianças de escolas públicas e particulares de Uruguaiana, Rio Grande do Sul - Brasil e Passo de Los Libres, Corrientes - Argentina sobre a castração e seus benefícios para os animais de estimação.

\section{Você sabe o que é castração e seus benfícios para os} animais?

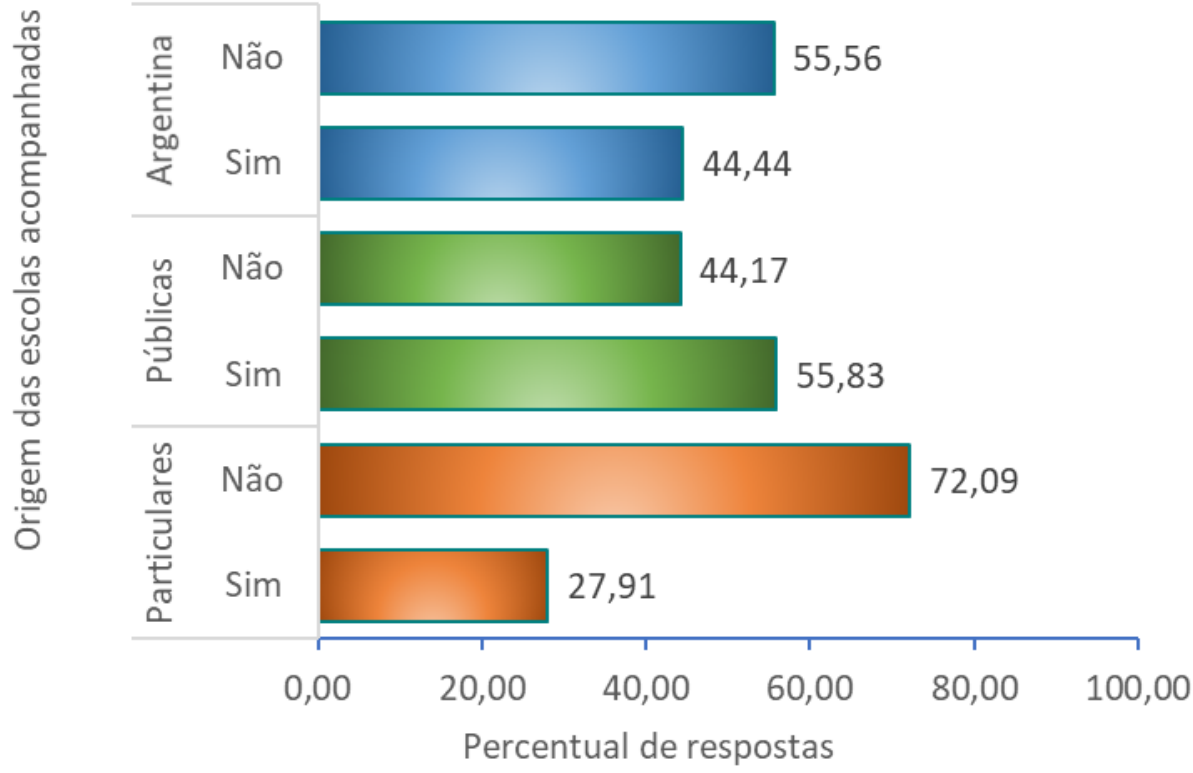

Fonte: Elaborado pelos autores

No que tange diretamente à saúde pública as crianças foram questionadas sobre o conceito de zoonoses, e se conheciam a doença transmitida pela mordida canina. No primeiro questionamento, independente de escolas privadas ou públicas e brasileiras ou argentinas, mais de 50\% das crianças desconheciam o conceito da expressão "zoonoses" (Figura 5). Atrelado a este desconhecimento, está também a falta de consciência do potencial de transmissão existente em seus próprios animais de estimação. Brandt et al., (2021) em seu estudo realizado em escolas de Uruguaiana em anos anteriores ao nosso com crianças de faixa etária semelhante, constatou que apenas 3,18\% sabiam que animais transmitiam doenças para os humanos, e que 96,82\% delas não possuíam esse conhecimento (Figura 9). Já Dias et al. (2012), também trabalhando com crianças em escolas de São Luiz do Maranhão, porém, de faixa etária superior (10 anos) constatou que $69,1 \%$ dos participantes reconheciam a possibilidade de se contrair alguma doença de animais, mesmo não sabendo o significado da palavra zoonose de forma integral. Oliveira Neto et al. (2018) ao entrevistar tutores adultos constatou que todos conheciam o potencial de animais em transmitir doenças para humanos, porém, quando indagados 
sobre o conceito de zoonoses, $74 \%$ não sabiam do que se tratava e $80 \%$ disseram nunca ter recebido esclarecimentos sobre tal assunto. Analisando-se esses dados, é notório que esse é um assunto que precisa de atenção, pois além de ser um tema que acarreta no bemestar do próprio animal, também é de interesse da saúde pública humana (Brandt et al., 2021). Um programa de controle de zoonoses depende de um manejo populacional canino e felino em área urbana. Este, para ser efetivo deve ser composto por um conjunto de estratégias que evitem a superpopulação e o abandono animal (GARCIA et al., 2018). Assim, além do entendimento da dinâmica e a caracterização dessas populações para o planejamento das ações, monitoramento e avaliação do programa de manejo populacional e de suas estratégias (GARCIA et al., 2018) as campanhas de conscientização são fundamentais para o sucesso destes programas.

Figura 5- Consciência de crianças de escolas públicas e particulares de Uruguaiana, Rio Grande do Sul - Brasil e Passo de Los Libres, Corrientes - Argentina sobre o conceito de zoonoses.

Você sabe o que são zoonoses?

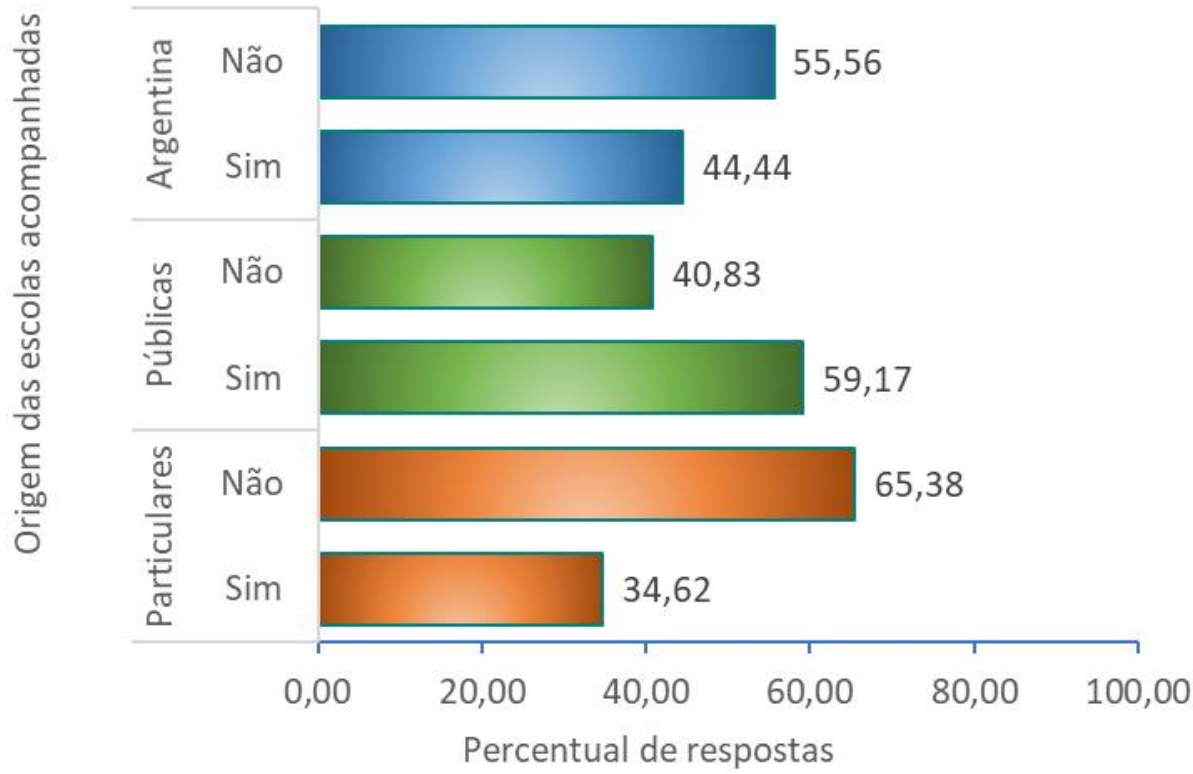

Fonte: Elaborado pelos autores

Ainda, ao serem questionados sobre a origem da raiva, um alto percentual de crianças das escolas argentinas $(92,59 \%)$ e da rede pública municipal de Uruguaiana $(87,92 \%)$ afirmaram conhecer a origem da zoonose. Enquanto nas escolas particulares, apenas $56,52 \%$ conheciam a forma de transmissão da doença. O conhecimento sobre essa zoonose é muito importante, pois os cães estão envolvidos na história natural desta 
(CEDIEL et. al., 2010) e de outras zoonoses como a leishmaniose (CRMV-SP, 2010) e principalmente doenças parasitárias (ALVES et al., 2013).

Figura 6 - Consciência de crianças de escolas públicas e particulares de Uruguaiana, Rio Grande do Sul - Brasil e Passo de Los Libres, Corrientes - Argentina sobre a transmissão da zoonose raiva.

Você sabe qual doença é transmitida pela mordida do cão?

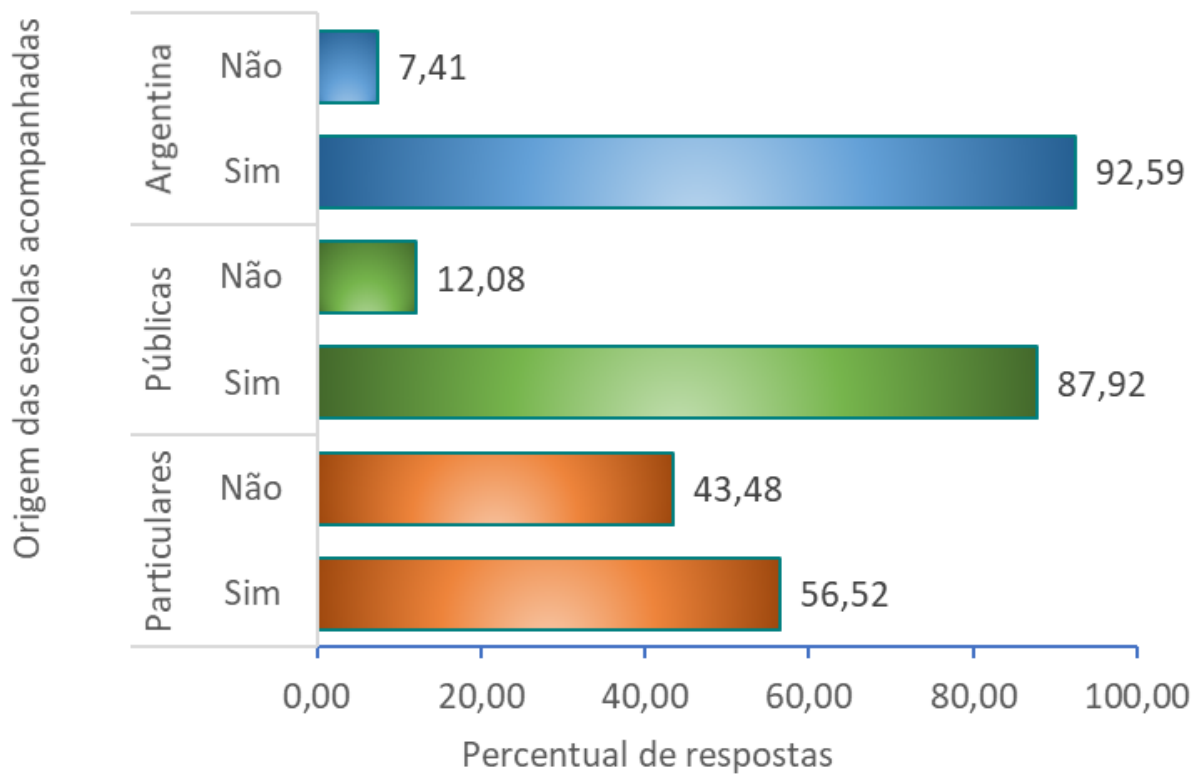

Fonte: Elaborado pelos autores

Ainda, em se tratando da raiva, mesmo que não ocorra a transmissão da doença, as implicações envolvidas com os casos de agressão aos humanos e a outros animais são muito preocupantes. As mordeduras caninas, além do risco de transmissão de zoonoses são consideradas causas importantes de morbidade e mortalidade pois comprometem tanto a integridade física como a psicológica das vítimas, especialmente se estas forem crianças (ALVES et al., 2013).

\section{CONSIDERAÇÕES FINAIS}

Os conhecimentos das crianças sobre posse responsável e zoonoses são limitados, porém, demonstram que existe mínima preocupação dos tutores com os animais. Ainda, os dados obtidos confirmam o grande potencial para trabalhos de conscientização nas escolas que devem ser continuados e podem estender-se aos pais das crianças. Também, 
nestes trabalhos de conscientização devem estar contempladas a posse responsável, bemestar animal e principalmente saúde pública com foco em zoonoses.

\section{REFERÊNCIAS}

ALVES A.J.S.; GUILOUX A.G.A.; ZETUN C.B.; POLO G.; BRAGA G.B.; PANACHÃO L.I.; SANTOS O.; DIAS R.A.; Abandono de cães na América Latina: revisão de literature. Revista de Educação Continuada em Medicina Veterinária e Zootecnia do CRMV-SP, v. 11, n. 2, p. $34-41,2013$.

ARRUDA, E.C.; NORONHA, J.; MOLENTO, C.F.M.; GARCIA, R.C.M.; OLIVEIRA, S.T. Características relevantes das instalações e da gestão de abrigos públicos de animais no estado do Paraná, Brasil, para o bem-estar animal. Arquivos Brasileiros de Medicina Veterinária e Zootecnia, v.71, n.1, p.232-242, 2019

CEDIEL N.; HOZ, F.; VILLAMIL, L.C.; ROMERO J.; DIAZ, A. Epidemiología de la rabia canina en Colombia. Rev. salud pública. v. 12, p. 368-379. 2010.

CRMV-SP. Conselho Regional de Medicina Veterinária do Estado de São Paulo. Informativo do Conselho Regional de Medicina Veterinária do Estado de São Paulo. v. 42. 2010.

DANTAS LOSS, L.; MUSSI, J.M.S.; MELLO, I.N.K.; LEÃO, MS.; FRANQUE, M.P. Responsible pet ownership and dog owners conduct in the county of Alegre-ES. Acta Veterinaria Brasilica, v.6, n.2, p.105-111, 2012.

DELARISSA, F. A. Animais de Estimação e Objetos Transicionais: Uma Aproximação psicanalítica sobre a interação criança-animal. 407f. 2003. Dissertação (Mestrado em Psicologia), Faculdade de Ciências e Letras, Universidade Federal de São Paulo, Assis, SP, 2003.

DIAS, I. C. L. GUIMARÃES, C. A.; MARTINS, D. F.; BRANDÃO, V. M.; SILVA, I. A. da; SILVA, M. I. S. Zoonoses e posse responsável: percepção e atitudes entre crianças do ensino fundamental. Revista de Ciência e Extensão, v.8, n.1, p.66-76, 2012.

DOTTI, J. Terapia e animais. 1. ed. São Paulo, 2014. 294p.

GARCIA, R. C. M., CALDERÓN, N., FERREIRA, F. Consolidação de diretrizes internacionais de manejo de populações caninas em áreas urbanas e proposta de indicadores para seu gerenciamento. Revisa Panamericana Salud Publica, v.32, n.1, $140-4,2012$.

GARCIA, R.C.M.; AMAKU M.; BIONDO A.W.; FERREIRA F. Dog and cat population dynamics in an urban area: evaluation of a birth control strategy. Pesquisa Veterinária Brasileira, v. 38, n.3, p.511-518, 2018.

JOFFILY, D.; SOUZA, M, L.; GOLÇALVES, M, S.; PINTO, V, J.; BARCELLOS, B, C, M.; ALONSO, S, L. Medidas para o controle de animais errantes desenvolvidas pelo 
grupo PET Medicina Veterinária da Universidade Federal Rural do Rio de Janeiro.

Revista de Ciência e Extensão, Uberlândia, 12, 197-211, 2013.

LOPES, M.H. et al. A Criança Descobrindo, Interpretando e Agindo sobre o

Mundo - Brasília: UNESCO, Banco Mundial, Fundação Maurício Sirotsky Sobrinho, 2005. 134p.

MARINHO, M. Conscientizar para o bem-estar: posse responsável. Revista de Ciência e Extensão, v.10, n.1, p. 65- 73, 2014.

MOLENTO, C.F.M. Public health and animal welfare. In: APPLEY, M.; WEARY, D.M.; SANDOE, P. Dilemmas in animal welfare. London: WSPA, 2014. p.102-123.

OLIVEIRA-NETO, R.R.; SOUZA, V.P.; CARVALHO, P.F.G.; FRIAS, D.F.R. Nível de conhecimento de tutores de cães e gatos sobre zoonoses. Revista de Salud Pública, v.20, n.2, p. 198-203, 2018.

PASA BRANDT, J. ., SOUZA DEBASTIANI, V., DAL MAGRO RIBEIRO, D. ., MARINHO TRINDADE, D., SANTARIANO SANT'ANNA, L., \& DALAZEN

CASTAGNARA, D. A percepção de crianças de uruguaiana - rs sobre zoonoses e posse responsável de animais. Recisatec - Revista Científica Saúde e Tecnologia, v.1, n. 2, p. e1214, 2021.

PFUETZENREITER, M. R.; ZYLBERSZTAJN, A.; AVILA-PIRES, F. D. Evolução histórica da medicina veterinária preventiva e saúde pública. Ciência Rural, v. 34, n.1, 2004.

SANTOS, F. S.; TÁPARO, C. V.; COLOMBO, G.; TENCAE, L. N.; PERRI, S. H. V.;

SEGATA, J. Nós e os outros humanos, os animais de estimação. Tese (Doutorado em Antropologia Social). Universidade Federal de Santa Catarina, Florianópolis, 2012.

SILVA, A.S.; SOUZA, R.P.; SANTOS, V.R.N.; SANTOS J.B.S.; SILVA, R.R.; SANTOS, P.L.; ALMEIDA. R.P.; CAMPOS, R. N.S. Abandono de animais: um problema de saúde pública em região do Nordeste, Brasil. Brazilian Journal of Development, v.7, n.3, p. 25666-25680, 2021.

SILVA, M. N. G. et al. Projeto "melhor amigo" na conscientização de guarda responsável de animais de estimação. Revista de Ciência e Extensão, v.9, n.1, p.43$52,2013$.

TEIXEIRA, G. N. R. d. F.; SILVA, J. A. M. C.; SOARES, D. F. d. M. Acumuladores de animais. Cadernos Técnicos de Veterinária e Zootecnia, n. 83, v. 1, p. 60-69, 2016. 